\title{
READMISSIONS FOR MORBIDITIES AMONG WOMEN WITHIN THE PUERPERIUM
}

\author{
Bhaktabatsal Raut ${ }^{1}$
}

\begin{abstract}
INTRODUCTION: There are varieties of morbidities which occurs during the postpartum period. The type and severities of such morbidities will determine the need for hospital readmission and appropriate treatment. To analyze the maternal morbidities among postpartum women who have been readmitted following discharge from the hospital after delivery.
\end{abstract}

MATERIAL AND METHODS: This was a hospital based descriptive study which was conducted including all women readmitted for postpartum complications within the puerperium after having been delivered at Paropakar Maternity and Women's Hospital, Thapathali, Kathmandu. The variables considered for study were pattern of postpartum morbidities, age and parity of women, mode of delivery and average duration of hospital stay.

RESULTS: The incidence of maternal postpartum readmission after having been delivered in study hospital was $1.25 \%$ $(\mathrm{n}=80)$, out of which puerperal sepsis was the most frequent diagnosis comprising $37.5 \%(\mathrm{n}=30)$, followed by secondary PPH $30 \%(n=24)$, urinary tract infections and hypertensive disorders of pregnancy. Seventy percentage of women were within the age group of 20-29 yrs and 56.3\% were primipara. When proportion of morbidities were analyzed among age groups of $\leq 19 \mathrm{yrs}$ and $\geq 20 \mathrm{yrs}$, and primiparity and multiparity, showed statistically insignificant difference. Sixty-six $(82.5 \%)$ women had vaginal delivery and $14(17.5 \%)$ had caesarean section. The percentage of readmission for postpartum morbidity among caesarean delivery was $1.43 \%$, and in vaginal delivery, it was $1.22 \%$. But this difference was statistically not significant ( $\mathrm{p}$ value $=0.59$ ). The average duration of hospital stay for postpartum morbidities was 4.53 days.

CONCLUSION: The incidence of maternal readmission for postpartum morbidities after having been delivered in the study hospital was $1.25 \%$, of which infectious morbidity was the commonest one. There is no statistically significant difference among morbidities between different age and parity groups. Women who had caesarean delivery were more likely to have postpartum morbidity requiring hospital readmission than women who had vaginal delivery but this difference was statistically not significant. Prevention and adequate treatment of infections in pregnancy, labor, delivery and postnatal period, and more stringent management of hypertensive disorders of pregnancy are mandatory to reduce the incidence of postpartum morbidity.

KEY WORDS: Morbidities; Puerperal sepsis; Postpartum hemorrhage; Variables

1. Obstetrician \& Gynecologist, Department of Obst.\& Gynaecology, Lumbini Zonal Hospital, Butwal, Nepal

\author{
For Correspondence \\ Dr. Bhaktabatsal Raut, MD \\ Obstetrician \& Gynecologist, \\ Department of Obst \& Gynaecology \\ Lumbini Zonal Hospital, Butwal, Nepal \\ E-mail:drbhakta_raut@yahoo.com
}




\section{INTRODUCTION}

WHO, 1998 defines the postpartum period, or puerperium as the period that begins one hour after delivery of the baby and placenta, and continues up to six weeks (42 days). ${ }^{1}$ The woman recovers from labor, adapts to her new role and reverts physically to her nonpregnant state during this period. Puerperium is a special but critical time for both the mother and her infant. During puerperium, the focus tends to be on the infant with relatively little interest paid to mother's health and needs. A significant proportion of maternal morbidity in puerperium is often undiagnosed and therefore neglected. Major obstetric morbidities include haemorrhage, sepsis, and pregnancy induced hypertension. Information on the extent of postpartum morbidity in developing countries is extremely limited. Data from hospital based studies is hard to interpret because of the small proportion of women that have access to medical care. Postpartum complications contribute to a lot of maternal morbidity and mortality. How often these complications arise and for which of the complications postpartum women seek health care is not very well documented and needs to be studied in depth. This information can help many of complications to be prevented or treated early.

A study done in Lusaka, Zambia in 2000, by Valley L and colleague, found that $1.7 \%$ of postpartum population in Lusaka will require hospital level care for postpartum complication of which puerperal sepsis was leading cause $(34.8 \%){ }^{2}$ Another hospital based retrospective study done by Shakuntala C and colleagues in India in 1999 to 2002; found that $2.2 \%$ (200) of total obstetric admissions (9080) during that period were due to postpartum complications. ${ }^{3}$ In the study hospital, $1.45 \%(n=285)$ of all obstetric admission $(19,568)$ was due to postpartum complications on reviewing hospital record of one year period from $16^{\text {th }}$ July 2005 to $15^{\text {th }}$ July 2006 but the different types of complications were not specified and recorded well. A retrospective analysis was done using hospital records of 240 cases admitted between $14^{\text {th }}$ April1995 to 17th October 1995 in the study hospital with third stage and puerperal complications. Results showed that $44.68 \%$ patients in the hospital delivered group were readmitted with diagnosis of puerperal sepsis and $29.78 \%$ of patients with secondary $\mathrm{PPH}{ }^{4}$

The challenge for today is making motherhood safe. The maternity and child healthcare including family planning needs to be improved, which requires an effort to improve the status of women through education, communication and social change. In fact every pregnancy is considered high risk and complications are usually not predictable. At the same time it is not possible for all women to give births in hospital and health institution. Encouraging domiciliary midwifery practices and producing skilled birth attendants in the communities will significantly reduce morbidity as well as mortality.

In the present study an attempt has been made to analyze the extent of morbidity in women readmitted in hospital with puerperal complications. This research is for the baseline assessment of the burden of moderate to severe morbidity in postpartum period requiring readmission following delivery in Paropakar Maternity and Women's Hospital with a view to monitor trends and identify risk factor, so that prevention and appropriate management can be planned accordingly to improve the quality of care given in the hospital.

\section{MATERIAL AND METHODS}

This was a hospital based descriptive study conducted at Paropakar Maternity and Women's Hospital, Thapathali, Kathmandu, Nepal. The period of study was from $18^{\text {th }}$ August, 2007- $15^{\text {th }}$ December 2007 . The study population was all postpartum readmissions for maternal morbidities after having delivered in the study hospital. The postpartum morbidities included were puerperal pyrexia, puerperal sepsis, post partum haemorrhage (PPH), hypertensive disorder of pregnancy, urinary tract infection (UTI), abdominal and perineal wound infections. All women who were admitted with postpartum morbidity but after 42 days of delivery were excluded. Similarly, women who develop postpartum complications during the period of hospital stay for delivery but before discharge and who admitted for baby's illness were also excluded.

The sampling was universal and purposive. Everyday the hospital admission record was checked from emergency room and a list of mothers who met inclusion criteria was prepared. The patients were then followed in the wards and identification along with all documents verified thoroughly and included in the sampling. A verbal consent was taken and the cases were selected for history taking and physical examination. The admitted patients in the ward were followed till the time of discharge and any changes in the diagnosis were documented as diagnosis at discharge. The duration of hospital stay for post partum morbidities were also recorded in the performa at discharge. During the study period, one case of puerperal pyrexia due to urinary tract infection left against medical advice, another one case was admitted twice within puerperium with the diagnosis of secondary post partum hemorrhage. The data collected was entered daily in the master chart and in the computer. Frequency distribution, mean, standard deviation were calculated for suitable variables. These findings were presented in tables, graphs and 
figures. $\mathrm{Z}$ test for proportion was applied for testing the significance. $P$ value was considered significant if $p<0.05$. SPSS programme was the software used for calculation and tabulation of data. The final results were discussed and conclusion was derived.

\section{RESULTS}

A total of 80 women were readmitted with various postpartum morbidities after having been delivered in the study hospital. There were a total of 136 postpartum admissions for postpartum maternal morbidities. The total numbers of deliveries in study hospital during the period of study were 6364 and total numbers of obstetric admissions were 6979. The incidence of maternal postpartum readmission after having been delivered in study hospital was $1.25 \%(\mathrm{n}=80)$ and this comprised of $1.14 \%$ of total obstetric admissions. Another 56 women were also admitted with postpartum morbidities during the period but they had delivery in the places other than study hospital, so they were excluded. Out of all 80 women readmitted with postpartum morbidities, puerperal sepsis was the most frequent diagnosis comprising 37.5\% $(n=30)$, followed by secondary PPH 30\% $(n=24)$. Urinary tract infections and hypertensive disorders of pregnancy were other diagnosis.

Table 1: Readmissions for morbidities in relation to age of patients

\begin{tabular}{|l|c|c|c|}
\hline Age & $\begin{array}{l}\text { Women } \\
\text { readmitted with } \\
\text { morbidity }\end{array}$ & $\begin{array}{l}\text { Women without } \\
\text { readmissions }\end{array}$ & Total delivery \\
\hline$\leq 19 \mathrm{yrs}$ & $\begin{array}{c}10 \\
(1.38 \%)\end{array}$ & $\begin{array}{l}711 \\
(98.61 \%)\end{array}$ & 721 \\
\hline$\geq 20 \mathrm{yrs}$ & 70 & 5573 & 5643 \\
& $(1.24 \%)$ & $(98.75 \%)$ & \\
\hline
\end{tabular}

When age of women readmitted with postpartum morbidities was analyzed, the readmission rate among teenagers $(\leq 19$ yrs) was $1.38 \%$ and $1.24 \%$ for $\geq 20 y r s$. The difference in the proportion of morbidity among total delivery of these two age groups was statistically not significant $(\mathrm{P}$ value $=0.73)$.

(Table 1)

Table 2: Readmissions for morbidities in relation to parity

\begin{tabular}{|l|c|l|l|}
\hline Parity & $\begin{array}{c}\text { Women readmitted } \\
\text { with morbidity }\end{array}$ & $\begin{array}{l}\text { Women without } \\
\text { readmissions }\end{array}$ & Total delivery \\
\hline Primipara & $\begin{array}{c}45 \\
(1.44 \%)\end{array}$ & $\begin{array}{l}3072 \\
(98.55 \%)\end{array}$ & 3117 \\
\hline Multiparity & 35 & 3212 & 3247 \\
& $(1.07 \%)$ & $(98.92 \%)$ & \\
\hline
\end{tabular}

When parity among the women readmitted with postpartum morbidity was analyzed, the readmission rate among primipara was $1.44 \%$ and $1.07 \%$ for multipara. The difference of proportion was statistically not significant, $p$ value $=0.19 .($ Table 2$)$.

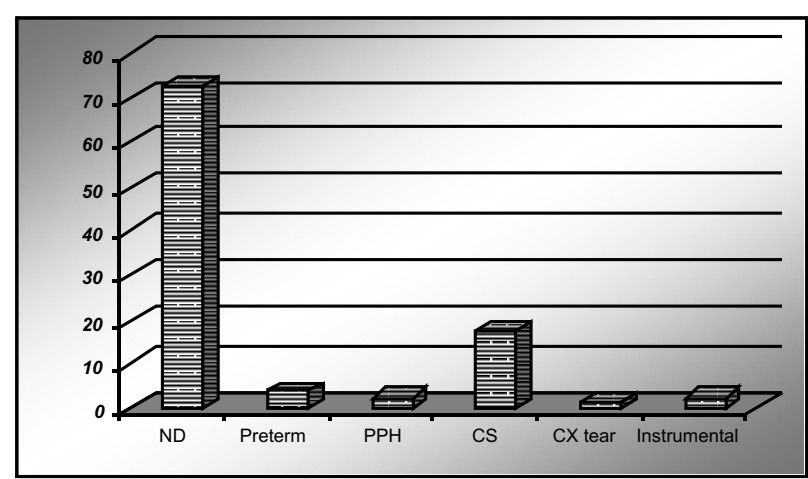

Figure 1: Readmissions for morbidities in relation to gestational age at delivery

During the period of study, a total of 6364 women delivered of which 80 women readmitted with postpartum morbidity. Sixty-six $(82.5 \%)$ women among them had vaginal delivery and $14(17.5 \%)$ women had caesarean section. Among women who had vaginal delivery, 58 (72.5\%) had normal delivery, and rest of $10 \%$ had abnormal vaginal delivery in the form of postpartum haemorrhage, preterm delivery, instrumental delivery and one women had vaginal delivery with cervical tear. (Fig. 1).

Table 3: Readmissions for morbidities in relation to mode of delivery

\begin{tabular}{|l|l|l|l|}
\hline MOD & $\begin{array}{l}\text { Women readmitted } \\
\text { with morbidity }\end{array}$ & $\begin{array}{l}\text { Women without } \\
\text { readmissions }\end{array}$ & $\begin{array}{l}\text { Total } \\
\text { delivery }\end{array}$ \\
\hline Vaginal Delivery & $66(1.22 \%)$ & $5319(98.88 \%)$ & 5385 \\
\hline $\begin{array}{l}\text { Caesarean } \\
\text { delivery }\end{array}$ & $14(1.43 \%)$ & $965(98.57 \%)$ & 979 \\
\hline
\end{tabular}

The percentage of women readmitted with postpartum morbidity in caesarean delivery was $1.43 \%$ where as in vaginal delivery, it was $1.22 \%$. But, the difference was statistically not significant, $\mathrm{p}$ value $=0.59$. (Table 3 ).

Among women readmitted for treatment of postpartum morbidities, the duration of hospital stay was within 2 days for $20 \%$ of women, $3-7$ days for $73.8 \%(n=59)$ of women and $>7$ days for $6.3 \%$ of women. Shortest duration was $24 \mathrm{hrs}$ and longest was 11 days.

The average duration of hospital stay was 4.57 days. 


\section{DISCUSSION}

The national safe motherhood program recommends that mother should have postnatal checkup within 3 days of delivery, of which first $24 \mathrm{hrs}$ is the most critical one, where greatest number of deaths occur. The national essential maternal and neonatal health care service package for Nepal recommends three postnatal visits for all women, whether delivered at home or in the other facility. The improvement of maternal health is one of the Millennium development goals. Measures to improve maternal health in the form of increasing skilled birth attendant and emergency obstetric care are expected to contribute to a decline in the burden of maternal mortality as well as morbidity. As this study looks at the late postpartum complications after patients were discharged, it indicates many of the possible complications that might have been missed during early postnatal period while the patients were still in the hospital; few of the complications had developed late in the course of the postpartum period.

The incidence of postpartum hospital admission for maternal morbidities in the study period was $1.94 \%(\mathrm{~N}=136)$ among which $80(1.25 \%)$ women got readmitted after having been delivered in the study hospital. The finding of postpartum hospital admission rate was similar with a descriptive study of Lusaka, Zambia. They found that at least $1.7 \%$ of the postpartum population in Lusaka will require hospital level care for postpartum complications. Among them puerperal sepsis was most common complication (34.8\%), others were malaria $14.5 \%$, pregnancy induced hypertension $10.9 \%$. Similar study done in India in 1999 -2002, found that $2.2 \%$ (200 cases) of all obstetric admissions (9080 cases) were due to postpartum complications.

The biggest proportion, 119 (56.5\%) of 200 women had been admitted after having been discharged from the study hospital ${ }^{3}$. The percentage of readmitted cases among total postpartum admission was similar as in this study where readmitted cases were $58.82 \%$ (80 of 136). Another study from Philadelphia Perinatal Database in 1994-1997 also showed that rehospitalization rate for postpartum morbidity was 21.6 per 1000 births $(2.16 \%){ }^{5}$ A retrospective study done in the year 1995, in the study hospital showed that $37.5 \%$ cases among 112 women with postpartum admissions were readmitted cases after having been delivered in the same hospital. ${ }^{4}$ Now, in the same hospital the rate was $58.82 \%$ in spite of the access of the women to other health facility as well as better care in the community is available nowadays. This suggested that the incidence of postpartum morbidity is increased in comparison to the past. Therefore, present status of quality of care provided during intrapartum and immediate postpartum period should be improved.
In this study, the incidence of puerperal sepsis among 6364 total birth was $0.47 \%(n=30)$. Women who were already diagnosed as puerperal sepsis and treated before discharge from hospital have not been included in the study. Also, some women might have developed sepsis and gone elsewhere for treatment would not be reflected in this study. This clearly indicates a need for more careful infection prevention practices. A postgraduate training course in reproductive health 2004, on the global incidence of puerperal sepsis, mentioned that incidence of puerperal sepsis showed variations among published papers. Two studies in Nigeria showed the incidence to be $1.49 \%$ and $1.36 \%$, where as in West Africa it was as low as $0.09 \%$. The reported incidence of Malawi was $1.34 \%$ and in Sierra Leone $5.38 \%$. One study in Australia reported an incidence rate of puerperal sepsis of $17 \%$ but this study was looking at population already at risk of puerperal sepsis. ${ }^{6}$

In this study, incidence of secondary PPH was $0.37 \%$ (24 in 6364 total deliveries), of which $62.5 \%$ women had surgical uterine evacuation and rest of them treated conservatively. A similar finding was obtained in a hospital based retrospective study done in Patan hospital in the year August 2005-August 2006. They found that the incidence of secondary postpartum hemorrhage was $0.42 \%$, which constituted $2.3 \%$ of total obstetric ward admissions ${ }^{7}$. A similar study also showed that secondary postpartum haemorrage occurs in just under $1 \%$ of women and is associated usually with primary postpartum haemorrage and retained placenta. There was a high associated morbidity, with $84 \%$ requiring hospital admission, $63 \%$ surgical evacuation, $17 \%$ blood transfusion. ${ }^{8}$

In this study, the incidence of postpartum urinary tract infection was found at $0.36 \%$, four cases among them presented as urinary retention. In a study done in Malaysia in 2006, prevalence of urinary tract infection during the puerperium was high ranging from $3-17 \%$ and postpartum urinary retention had a reported incidence of $1.7-17.9 \%$.

In this study the incidence of readmission due to postpartum morbidity in age group of $\leq 19 \mathrm{yrs}$ and $\geq 20$ yrs was found at $1.38 \%(\mathrm{n}=10)$ and $1.24 \%(\mathrm{n}=70)$ respectively. The difference in the proportion of morbidity among total delivery of these two age groups was statistically not significant $(\mathrm{p}$ value $=$ 0.73). Another retrospective analysis done in this study hospital in 1995, showed that a quarter of patients in each study group (delivered in the study hospital and outside) were teen aged mothers. About $8 \%$ of patients in the group delivered outside were above the age of $35 y$ rs. ${ }^{4}$ Similarly, a retrospective study conducted at Nepal medical college teaching hospital, Jorpati in 2004 reported that, among 1619 postpartum admissions $57.9 \%$ were between $20-25$ years and $17 \%$ were teenagers. ${ }^{10}$ In a retrospective hospital based study 
in India in 2002, showed that teenagers were just 4\%, $82 \%$ between 20-29years of age, and 14\% between $30-39$ years. ${ }^{3}$ Similarly, a hospital based retrospective study of cases of secondary postpartum haemorrhage in Patan hospital in 2006, showed that $79 \%$ of cases were in the age group of $20-29$ years and $4.6 \%$ at $\leq 19$ yrs of age.

Regarding the parity of women readmitted for postpartum morbidity in this study, $56.3 \%(\mathrm{n}=45)$ were primapara, $41.3 \%$ $(n=33)$ with parity $2-3$, and $2.5 \%(n=2)$ with parity 4 and above. The incidence of readmission for postpartum morbidity among primipara was $1.44 \%(n=45)$ and among multi parity was $1.07 \%(n=35)$. The difference in proportion between the two was statistically not significant ( $\mathrm{p}$ value $=$ 0.19). In a retrospective study done in this hospital in 1995 showed that $70 \%$ of patients readmitted with puerperal complications were primipara. On the group delivered outside, $15 \%$ were multipara and a majority was women with high parity ${ }^{4}$ Another retrospective study conducted at Nepal medical college teaching hospital, Jorpati in 2004 showed $88(5.4 \%)$ primipara among total postpartum admissions. ${ }^{10}$ Similarly, a retrospective hospital based study done in India in 2002 , showed that majority of women (44\%) were primipara, $31 \%$ belong to parity $2,24 \%$ parity 3 and 4 , and 2 were grandmultipara. ${ }^{3}$ The findings in relation to parity were quite similar with this study. In a hospital based retrospective study of cases of secondary postpartum haemorrhage in Patan hospital in 2006, showed that $65 \%$ of women were primipara and $26.3 \%$ in their second parity. ${ }^{7}$

During the period of this study, a total of 6364 women delivered, of which 80 women readmitted with postpartum complications. Sixty-six $(82.5 \%)$ women among them had vaginal delivery and $14(17.5 \%)$ women had caesarean section. Incidence of postpartum readmission who had caesarean section was $1.43 \%$ and vaginal delivery was $1.22 \%$. The difference was statistically not significant ( $\mathrm{p}$ value 0.59 ). The comparison with instrumental delivery was not made as the sample size of instrumental delivery was very low to interpret. In this study, among women readmitted for treatment of postpartum morbidities, the duration of hospital stay was within 2 days for $20 \%, 3-7$ days for $73.8 \%$ and $>7$ days for $6.3 \%$. A population based cohort study conducted in Canada between 1998 and 2001 showed that, caesarean delivery was associated with significantly increased risk of postpartum readmission compared to spontaneous vaginal delivery. The length of hospital stay after rehospitalization averaged 3.5 days for CS, 2.9 days for forceps and 2.7 days for both vacuum and spontaneous vaginal delivery. ${ }^{11}$ Another retrospective cohort study of data from the Washington state Birth Events Record Database for 1996 showed that women with caesarean section and assisted vaginal deliveries were at increased risk for rehospitalization, particularly with infectious morbidities. Rehospitalization was high among women with caesarean delivery (RR 1.8; 95\% CI, 1.6-1.9), assisted vaginal delivery ( $R R 1.3 ; 95 \% \mathrm{CI}, 1.2-1.4$ ) in comparison to spontaneous vaginal delivery. ${ }^{12}$ In a prospective study done in the year 1990-2005, at University teaching hospital Nigeria, comparison was made between elective caesarean section with vaginal delivery and showed that incidence of postpartum febrile morbidity was $11 \% \mathrm{vs}$. $4.7 \%$, readmissions $4.3 \%$ vs. $1.4 \%$, mean hospital stay $13.3 \pm 8.8$ vs. $6.2 \pm 5.4$ days respectively. ${ }^{13}$

\section{CONCLUSION}

The incidence of maternal readmissions for postpartum morbidities after having been delivered in the hospital was $1.25 \%$ among total birth. The commonest morbidity requiring hospital readmission was puerperal sepsis comprising $37.5 \%$, followed by secondary PPH $30 \%$, urinary tract infection $23 \%$, and hypertensive disorders of pregnancy in $8.8 \%$ of women. Seventy women were $\geq 20$ yrs of age and 10 of them $\leq 19$ yrs. The proportion of morbidity of readmitted women in these age group among total delivery was statistically not significant ( $p$ value $=0.73)$. Similarly, $56.3 \%(n=45)$ of women with parity one, had readmission for postpartum morbidity but the proportion of morbidity in primipara and multiparity among these group of total delivery was also statistically not significant $(\mathrm{p}$ value $=0.19)$. Women who had caesarean delivery were more likely to have postpartum morbidity requiring hospital readmission $(1.43 \%)$, than women who had vaginal delivery $(1.22 \%)$, but this was not statistically significant, $(\mathrm{p}$ value $=0.59)$. The average duration of hospital stay for treatment of postpartum morbidity was 4.53 days. The recommendation is for prevention and adequate treatment of infections in pregnancy, labor, delivery and postnatal period, and more stringent management of hypertensive disorders of pregnancy to reduce the incidence of postpartum morbidity.

\section{REFERENCES}

1. World Health Organization: Postpartum care of mother and newborn: a practical guide. WHO/RHT/MSM/98.3.Geneva:WHO;1998.

2. Vallely L, Ahmed Y, Murray SF. Postpartum maternal morbidity requiring hospital admission in Lusaka, Zambia: a descriptive study. BMC pregnancy and childbirth 2005, 5:1

3. Shankuntala C, Verma S, Ritambara B. Quality of postpartum care. JObstet Gynecol India 2006; 56: 142-146.

4. Sharma S, Padhye SM. Third stage and puerperal complications 
in admissions at the Maternity Hospital. Smarika 2053 B.S. (1996); 85-97.

5. Webb DA, Robbins JM. Mode of delivery and risk of postpartum rehospitalization. JAMA 2003; 289: 46-47 http://dx.doi.org/10.1001/jama.289.1.46-b

6. Chisembela M. The Global incidence of puerperal sepsis: postgraduate Training course in reproductive health 2004. Lusaka, Zambia.

7. Sharma P, Regmi M. Secondary PPH: A retrospective descriptive study. Journal of society of surgeons of Nepal 2007; 10(3): 7-10.

8. Hoveyda F, Mackenzie IZ, Secondary postpartum haemorrhage: incidence, morbidity and current management. BJOG 2001; 108: 927

http://dx.doi.org/10.1111/j.1471-0528.2001.00230.x

http://dx.doi.org/10.1016/S0306-5456(01)00230-3

9. Zainur RZ, Loh KY. Postpartum morbidity: what can we do. Medical journal of Malaysia 2006; 61(5): 242-246.

10. Tuladhar H, Dali SM, Pradhanang V. Complications of home delivery: a retrospective analysis. JNMA 2005; 44 (159): 87-91

11. Liu S, Heaman M, Joseph KS, Liston RM, Huang L, Sauve R, Kramer MS. Risk of maternal postpartum readmission associated with mode of delivery. Obstetric and Gynaecology (New York) 2005; 105:836-842.

http://dx.doi.org/10.1097/01.AOG.0000154153.31193.2c

PMid:15802414

12. Lydon-Rochelle M, Holt VL, Martin DP, Easter Ling TR. Association between method of delivery and maternal rehospitalization. JAMA 2000; 283(18): 2411-2416.

http://dx.doi.org/10.1001/jama.283.18.2411

PMid:10815084

13. Oladapo OT, Lamina MA, Sule-odu AO. Maternal morbidity and mortality associated with elective caesarean delivery at university Hospital in Nigeria. The Australian and New Zealand Journal of Obstetrics and Gynaecology 2007; 47: 110-114. http://dx.doi.org/10.1111/j.1479-828X.2007.0 